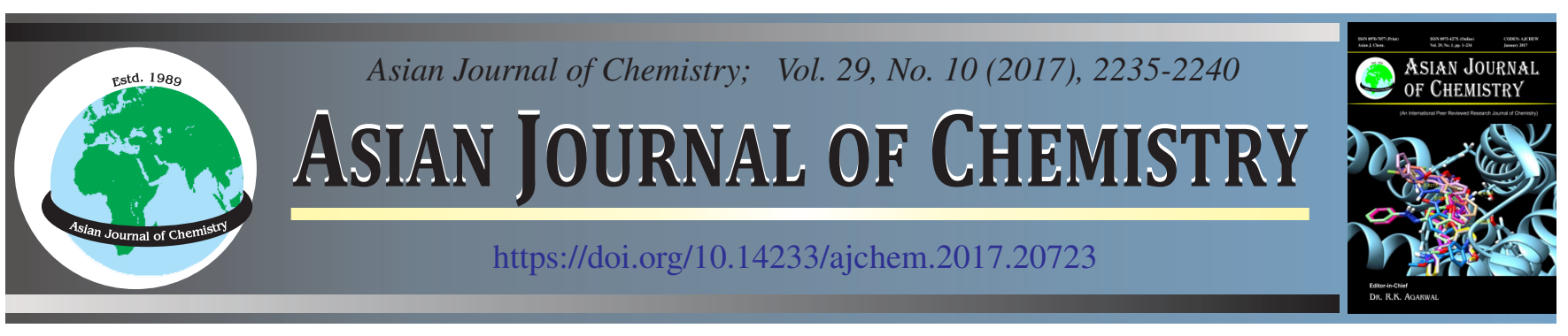

\title{
Variation of Energy Absorption and Exposure Build-up Factor Dependence with Effective Atomic Number and Electron Density of Amino Acids
}

\author{
Rajkumar M. Lokhande ${ }^{*}$, Bharat S. Surung and Pravina P. Pawar
}

Department of Physics, Dr. Babasaheb Ambedkar Marathwada University, Aurangabad-431 004 India

*Corresponding author: E-mail: rajm1358@gmail.com

Keywords: Energy absorption build-up factor, Energy absorption build-up factor, Geometrical progression method, Amino acids.

ᄂ - - - - - - - - - - - - - - - - - - - - - - - - - - - -

\section{INTRODUCTION}

The study of $\gamma$-radiation interaction with matter having changes in physical and chemical properties are very important role in shielding because radiation is harmful for living organisms as reported by Manohara et al. [1]. The basic quantities mass attenuation coefficient, effective atomic number $\left(\mathrm{Z}_{\mathrm{eff}}\right)$, i.e., effective electron density $\left(\mathrm{N}_{\text {eff }}\right)$, energy absorption build-up factor (EABF) and exposer build-up factor (EBF) studied the interaction of $\mathrm{X}$-ray and gamma photon with matter were used in the medical, radiation dosimetry, radiation protection, radiation biophysics and biosensor [2,3]. There are two types of build-up factors: (a) Energy absorption build-up factor (b) exposure build-up factor. The energy absorption build-up factor in which the quantity of interest is the absorbed or deposited energy in the interacting material and the detector response function is that of absorption in the interacting material as reported by Kurudirek et al. [4]. Exposer build factor is the ratio of density due to total flux and density due to uncoiled flux. The study of energy absorption and exposure build-up factor of soil, biological material, space materials, tissue, teeth, space sample, concrete fly ash and amino acid discussed [5-8]. Different methods were used by various research groups to compute the build-up factors geometrical progression (G-P) fitting method as suggested by Harima et al. [9], invariant embedding method as suggested by Sakamaoto et al. [10] and
Shimizu et al. [11], iterative method as suggested by Suteau \& Chiron et al. [12] and Monte Carlo method as suggested by Sardari et al. [13]. Study of build-up factor help to detect or knowledge of scattered photon, radiation interacts with human body and dose level to radiotherapy patients [14]. The status of $\gamma$-ray shielding calculation for build-up factor comparison with American National Standards (ANS) and Atomic Energy Society of Japan (AESJ) standard database and G-P fitting method up to penetration depth upto $100 \mathrm{MFP}$ as suggested by Sakamoto et al. [15].

The amino acids are a basic building block of living organism. The human body uses 20 different amino acids for building peptides and proteins. The present study involves the mass attenuation coefficient, effective atomic number; effective electron density calculated in the wide energy region $1 \mathrm{keV}$ to $100 \mathrm{GeV}$ and energy absorption build-up factor and exposer build-up factor at 0.015 to $15 \mathrm{MeV}$ up to different penetration depth $40 \mathrm{mfp}$. This study reflects the dose distribution in the biological material by X-ray and gamma photon at 0.015 to $15 \mathrm{MeV}$ up to different penetration depth $40 \mathrm{MFP}$.

\section{EXPERIMENTAL}

The mass attenuation coefficients of selected amino acid were calculated by using NIST XCOM database for $1 \mathrm{keV}$ to $100 \mathrm{GeV}$. 
The effective atomic number calculated by

$$
\mathrm{Z}_{\mathrm{eff}}=\frac{\sigma_{\mathrm{t}}}{\sigma_{\mathrm{e}}}
$$

Firstly, we calculate the total attenuation cross section and electronic cross section.

Total attenuation cross section

$$
\sigma_{\mathrm{t}}=\frac{1}{\mathrm{~N}_{\mathrm{A}}} \sum \mathrm{f}_{\mathrm{i}} \mathrm{A}_{\mathrm{i}}\left(\mu_{\mathrm{m}}\right)
$$

where $\mathrm{N}_{\mathrm{A}}$ is the Avogadro constant, $\mu_{\mathrm{m}}$ is the mass attenuation coefficient and $A_{i}$ is the molar mass of the sample. $\Sigma f_{i}=1\left(f_{i}\right.$ is the mole fraction).

Electronic cross section:

$$
\begin{aligned}
\sigma_{e} & =\frac{1}{N_{A}} \Sigma_{i} \frac{f_{i} A_{i}}{Z_{i}}\left(\mu_{m}\right)_{i} \\
& =\frac{\sigma_{t}}{\Sigma Z_{\text {eff }}}
\end{aligned}
$$

Electronic cross section is the ratio of total attenuation cross section and effective atomic number.

Effective electron density: Effective electron density shows that the number of electron per unit mass.

$$
\mathrm{N}_{\text {eff }}=\left(\frac{\mathrm{N}_{\mathrm{A}}}{\mathrm{A}_{\text {eff }}}\right) \times \mathrm{Z}_{\text {eff }}
$$

where $\mathrm{A}_{\text {eff }}$ is effective atomic mass also known as the ratio of atomic weight and total number of atom

Computation of energy absorption build-up and exposure build-up factor: The computation of EABF using G-P fitting method and equivalence atomic number of selected amino acids. There are three steps:

- Calculate equivalence atomic number $\left(\mathrm{Z}_{\mathrm{eq}}\right)$.

- Computation of geometric progression (G-P) parameters.

- Calculating the energy absorption build-up factor.

Calculate equivalence atomic number $\left(Z_{\mathrm{eq}}\right)$ : The $\mathrm{Z}_{\mathrm{eq}}$ is depends on the chemical composition of materials. The different energy shows the different interaction processes such as photoelectric, Compton, pair production [4]. The $\mathrm{Z}_{\mathrm{eq}}$ defined by for the computation of equivalent atomic number, the ratio Compton partial attenuation coefficient $\left(\mu_{\mathrm{m}}\right)_{\text {comp }}$ and total attenuation coefficient $\left(\mu_{\mathrm{m}}\right)_{\text {total }}$ interacting material have been interpolated within the corresponding ratios $\left(\mu_{\text {Comp }} / \mu_{\text {total }}\right)$ database of the elements in the same energy $(0.015-15 \mathrm{MeV})$. The total mass attenuation coefficient $\left(\mu_{\mathrm{m}}\right)_{\mathrm{comp}}$ and partial Compton attenuation coefficient $\left(\mu_{\mathrm{m}}\right)_{\text {total }}$ were calculated by using NIST- XCOM database [16].

$$
\mathrm{Z}_{\text {eq }}=\frac{\mathrm{Z}_{1}\left(\log \mathrm{R}_{2}-\log \mathrm{R}\right)+\mathrm{Z}_{2}\left(\log \mathrm{R}-\log \mathrm{R}_{1}\right)}{\log \mathrm{R}_{2}-\log \mathrm{R}_{1}}
$$

where $\mathrm{R}$ is the ratio of selected biological materials at given energy. The $\mathrm{Z}_{1}$ and $\mathrm{Z}_{2}$ are the elemental atomic number corresponding to the ratio $\mathrm{R}_{1}$ and $\mathrm{R}_{2}$ respectively.

Computation of geometric progression (G-P) parameters: The build-up factor data for 23 elements, one compound, two mixtures (air and water) and concrete at energies in the range $0.015-15 \mathrm{MeV}$ up to penetration depths of 40 mfp using the G-P method provided by American National Standards (ANSI/ANS-6.4.3) [17]. Using the interpolation formula, five G.P. fitting parameters (b, c, a, $\mathrm{X}_{\mathrm{k}}$ and d) for selected samples were computed at the different incident photon energies using equivalent atomic number $\left(\mathrm{Z}_{\mathrm{eq}}\right)$, in the chosen energy range $(0.015 .15 .0 \mathrm{MeV})$ up to penetration depth of $40 \mathrm{mfp}$. The formula used for the purpose of interpolation is:

$$
\mathrm{C}=\frac{\mathrm{C}_{1}\left(\log \mathrm{Z}_{2}-\log \mathrm{Z}_{\mathrm{eq}}\right)+\mathrm{C}_{2}\left(\log \mathrm{Z}_{\mathrm{eq}}-\log \mathrm{Z}_{1}\right)}{\log \mathrm{Z}_{2}-\log \mathrm{Z}_{1}}
$$

where $C_{1}$ and $C_{2}$ are the values of the coefficients of G-P fitting parameters corresponding to the atomic numbers $\mathrm{Z}_{1}$ and $\mathrm{Z}_{2}$, respectively at a given energy and $\mathrm{Z}_{\mathrm{eq}}$ is the equivalent atomic number of the given material.

Computation of energy absorption build-up factor: Firstly, computed G-P fitting parameters were then used to compute the energy absorption and exposure build-up factors for the selected samples at some standard incident photon energies up to the penetration depth of 40 mean free paths of shielding thickness as given by following equations, with the help of G-P fitting formula:

$$
\begin{gathered}
\mathrm{B}(\mathrm{E}, \mathrm{X})=1+\frac{\mathrm{b}-1}{\mathrm{~K}-1}(\mathrm{Kx}-1) \quad \text { at } \mathrm{K} \neq 1 \\
\mathrm{~B}(\mathrm{E}, \mathrm{X})=1+(\mathrm{b}-1) \quad \text { at } \mathrm{K}=1 \\
\mathrm{~K}(\mathrm{E}, \mathrm{X})=\mathrm{cx}^{\mathrm{a}}+\mathrm{d} \frac{\tan \mathrm{h}\left(\frac{\mathrm{X}}{\mathrm{X}_{\mathrm{k}}}-2\right)-\tan \mathrm{h}(-2)}{1-\tan \mathrm{h}(-2)}
\end{gathered}
$$

where parameters $\mathrm{b}$ and $\mathrm{K}$ are corresponding to a build-up factor at $1 \mathrm{MFP}$ and a multiplication factor of dose through 1 MFP photon penetration respectively. Parameter $\mathrm{K}$ is obtained by for $\mathrm{X}$ using parameters $\mathrm{b}, \mathrm{c}, \mathrm{a}, \mathrm{d}$ and $\mathrm{X}_{\mathrm{k}}$.

\section{RESULTS AND DISCUSSION}

Calculated photon interaction parameter total mass attenuation coefficients $\left(\mu_{\mathrm{m}}\right)$, of selected amino acid in the wide energy range $1 \mathrm{keV}$ to $100 \mathrm{GeV}$ using NIST XCOM database are graphically represented in Fig. 1. It reflects the behaviour of photon energy increases mass attenuation coefficients decreases. The $\mu_{\mathrm{m}}$ depending on chemical composition and physical parameter of the composite material discussed by ElKhayatt et al. [18]. In energy region $0.01 \mathrm{MeV}<\mathrm{E}<0.05$ $\mathrm{MeV}$ shows the maximum variation with increasing photon energy of mass attenuation coefficients decreasing value of amino acids. From eqns. 1 and 4 calculate the effective atomic number and effective electron density of the amino acids (Figs. 2 and 3$)$. At same energy, the effective atomic number $\left(Z_{\text {eff }}\right)$ is dependence with energy, energy is increased $Z_{\text {eff }}$ decreases spontaneously (Fig. 2). Compton scattering interaction process of the composite material depends on the effective atomic number. N-Acetyl glutamic acid has maximum and D-threonine has minimum value of the effective atomic number. Effective electron density $\left(\mathrm{N}_{\text {eff }}\right)$ was measured the probability distribution of electron, effective electron density with incident energy graphically. Fig. 3 shows that the $\mathrm{N}$-acetyl glutamic acid has 


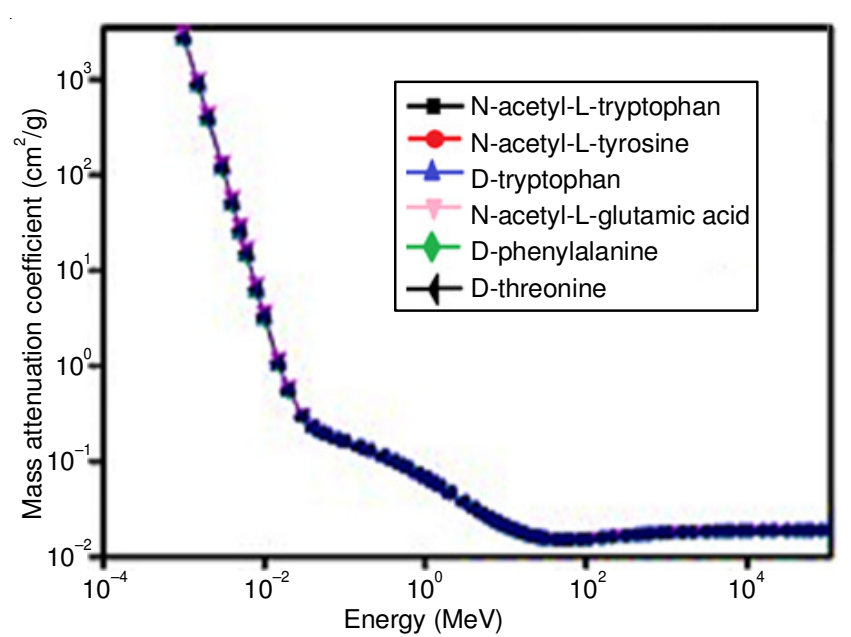

Fig. 1. Variation of mass attenuation coefficient with incident photon energy $1 \mathrm{keV}$ to $100 \mathrm{GeV}$

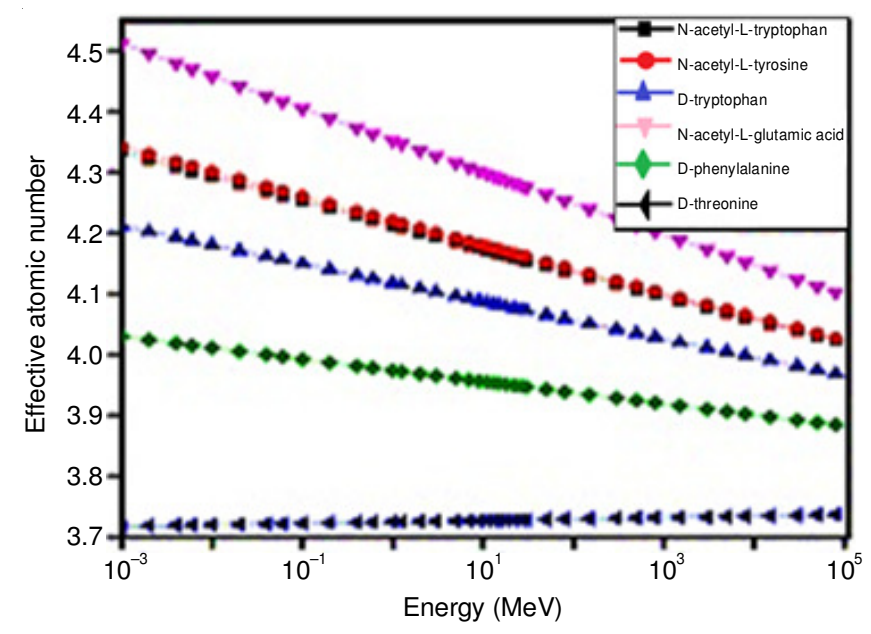

Fig. 2. Variation of $\mathrm{Z}_{\mathrm{eff}}$ with incident photon energy $1 \mathrm{keV}$ to $100 \mathrm{GeV}$

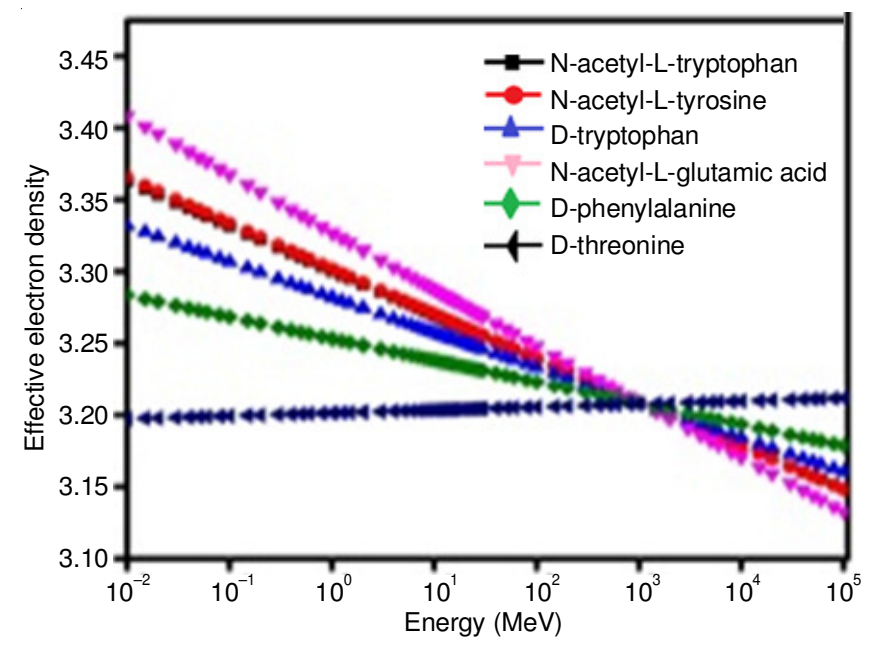

Fig. 3. Variation of $\mathrm{N}_{\text {eff }}$ with incident photon energy $1 \mathrm{keV}$ to $100 \mathrm{GeV}$

maximum value $3.41 \times 10^{23}$ electron $/ \mathrm{cm}^{3}$ at $1 \mathrm{keV}$ and minimum $3.13 \times 10^{23}$ electron $/ \mathrm{cm}^{3}$ at $100 \mathrm{GeV}$. In energy region, $100 \mathrm{keV}$ $<\mathrm{E}<1500 \mathrm{keV}$ does not show the variation of $\mathrm{Z}_{\text {eff }}$ and $\mathrm{N}_{\text {eff }}$ [19]. The wide energy range $1 \mathrm{keV}$ to $100 \mathrm{GeV}$ of amino acids, borate glass materials, narcotic drugs as earlier discussed by Manohara et al. [14], Sayyed et al. [20] and Gounhalli et al.
[21]. By comparing the present results with them have nearly the same behaviour.

Variation of EABF and EBF with incident photon energy: The variation of EABF and EBF of selected amino acids was shown in Fig. 4(a-d) and Fig. 5(a-d) with incident photon energy $0.015-15 \mathrm{MeV}$ up to penetration depth $1 \mathrm{MFP}$, 10 MFP, 20 MFP, 40 MFP using G-P fitting method. The photoelectric process $\left(\mathrm{E}_{\mathrm{pe}}\right)$ shows the lowest energy region in this region $\mathrm{EABF}$ and $\mathrm{EBF}$ increases slightly with increasing photon energy by definition $\mathrm{E}_{\mathrm{pe}}$ directly to $\mathrm{Z}^{2}$ and inversely to $\mathrm{E}^{3}$. This shows the photoelectric process is dominant in lower energy region. The value of incident photon energy increases $\mathrm{EABF}$ and $\mathrm{EBF}$ is enhancing in an intermediate region. The Compton scattering is main interaction process because of multiple scattering photon living longer time in materials. Energy was increasing EABF and EBF simultaneously decreasing their pair production is a main interaction process. Present study shows the observed behaviour of interaction process with EABF and EBF showed graphically as $\mathrm{E}_{\mathrm{pe}}<\mathrm{E}_{\mathrm{comp}}>\mathrm{E}_{\mathrm{pp}}$. D-Phenylalanine has the highest value of EABF and EBF, which nearly equal to $10^{4}$ at penetration depth $40 \mathrm{MFP}$ and $\mathrm{N}$-acetyl glutamic acid has the lowest value of EABF and EBF in $0.015-15 \mathrm{MeV}$ energy range. The value of $Z_{\mathrm{eq}}$ is high $\mathrm{EABF}$ and $\mathrm{EBF}$ is maximum conversely the value of $Z_{\mathrm{eq}}$ is low $\mathrm{EABF}$ and $\mathrm{EBF}$ is minimum. This result reflects the $\mathrm{EABF}$ and $\mathrm{EBF}$ are depend on the chemical composition of amino acids.

Variation of EABF and EBF dependence with penetration depth: The EABF and EBF as a function of penetration depth up to $40 \mathrm{MFP}$ at $0.1 \mathrm{MeV}$ incident photon energy graphically shown in Fig. 6 this shows the value of EABF and EBF was increased with increasing penetration depth. The Dphenylalanine EABF and EBF were maximum and $\mathrm{N}$-acetyl glutamic acid EABF and EBF were minimum at $0.1 \mathrm{MeV}$ at penetration depth upto 40 MFP. Graphically N-acetyl-tyrosine and D-tryptophan has shown the same nature.

Variation of EABF and EBF dependence with $\mathrm{Z}_{\mathrm{eff}}$ and $\mathbf{N}_{\text {eff }}$ : The $Z_{\text {eff }}$ is basic parameter used in medical diagnosis. We studied $Z_{\text {eff }}$ of amino acids with EABF and EBF at 40 MFP at different incident photon energy shown in Fig. 7. The highest value of $Z_{\text {eff }}$ as comparing EABF and EBF is at $0.1 \mathrm{MeV}$ and lowest at $0.015 \mathrm{MeV}$. At $0.15 \mathrm{MeV}$ shows the behaviour of an effective atomic number of D-phenylalanine (comparing with $\mathrm{N}$-acetyl glutamic acid) is low shows the value of EABF and $\mathrm{EBF}$ is maximum conversely effective atomic number of $\mathrm{N}$ acetyl glutamic acid is high shows the value of EABF and EBF was minimized. This result reflects that the effective atomic number increases EABF and EBF were decreasing. This result reflects that the effective atomic number increases EABF and EBF were decreasing. The electron density had been studied earlier using scattered photon energy; the Compton scattering is a main interaction process for normal and diseased breast tissue types [22]. Here we have explained the properties of energy absorption and exposure with electron density $\left(\mathrm{N}_{\text {eff }}\right)$ of amino acid at 0.015 to $15 \mathrm{MeV}$ up to penetration depth 40 MFP result shows the highest EABF and EBF value their Compton scattering was dominant in Fig. 7, which shows the behaviour of electron density with EABF and EBF. The importance of these radiobiological parameter data before the radiological 

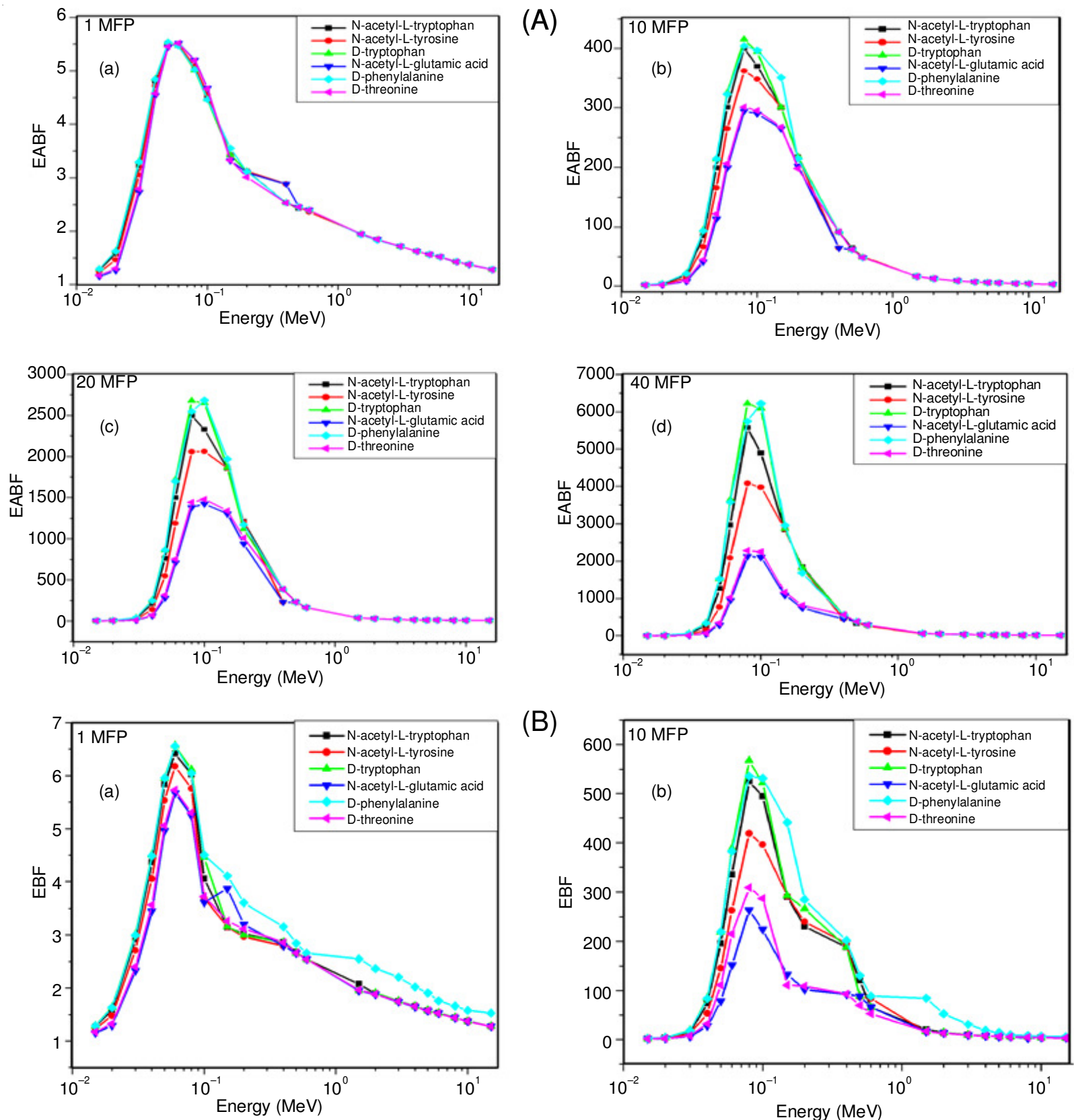

(B)
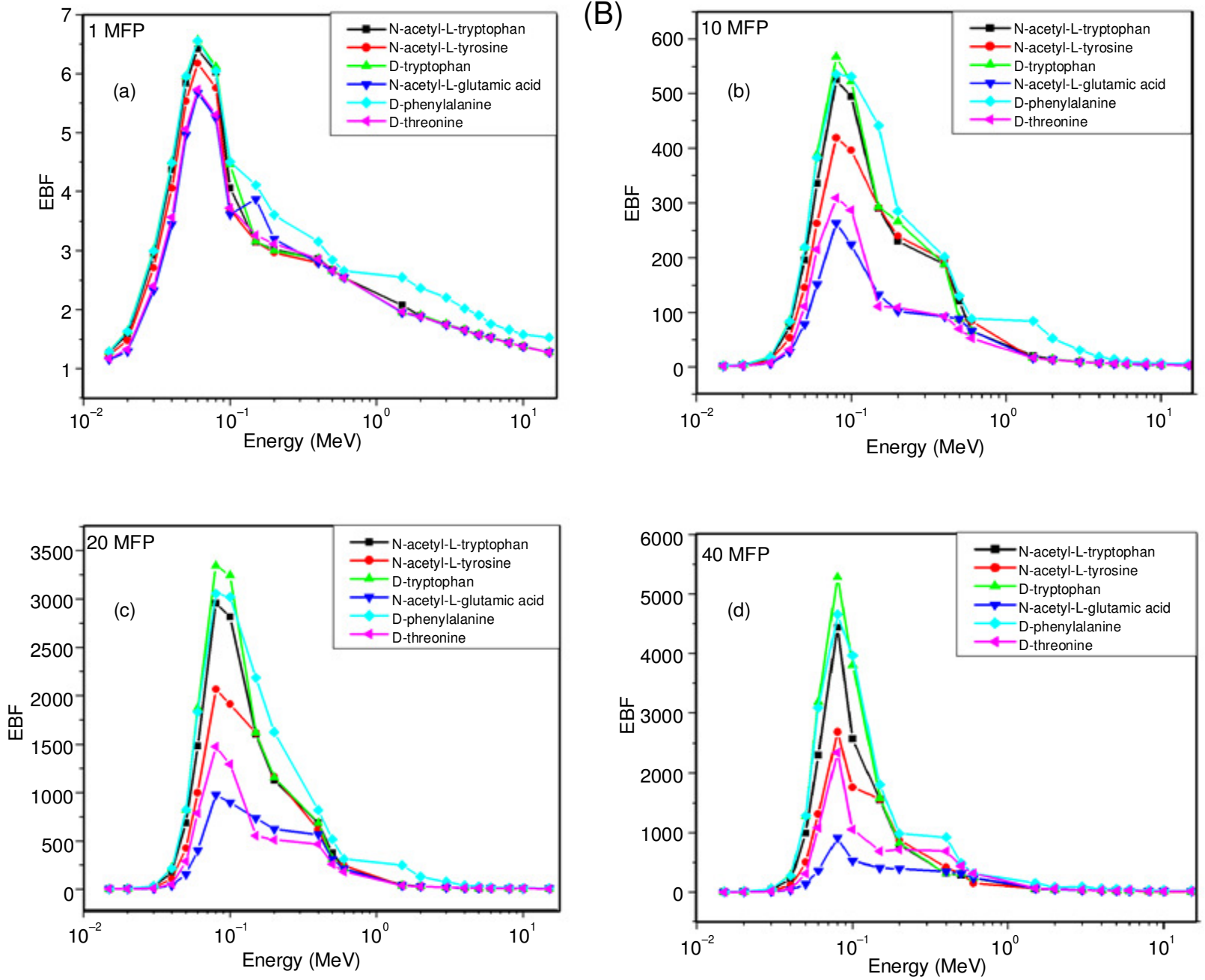

Fig. 4. (A) Variation of EABF and (B) Variation of EBF with incident photon energy 0.015 to $15 \mathrm{MeV}$ at penetration depth (a) 1 mfp, (b) 10 mfp, (c) $20 \mathrm{mfp}$, (d) $40 \mathrm{mfp}$ of selected amino acids 

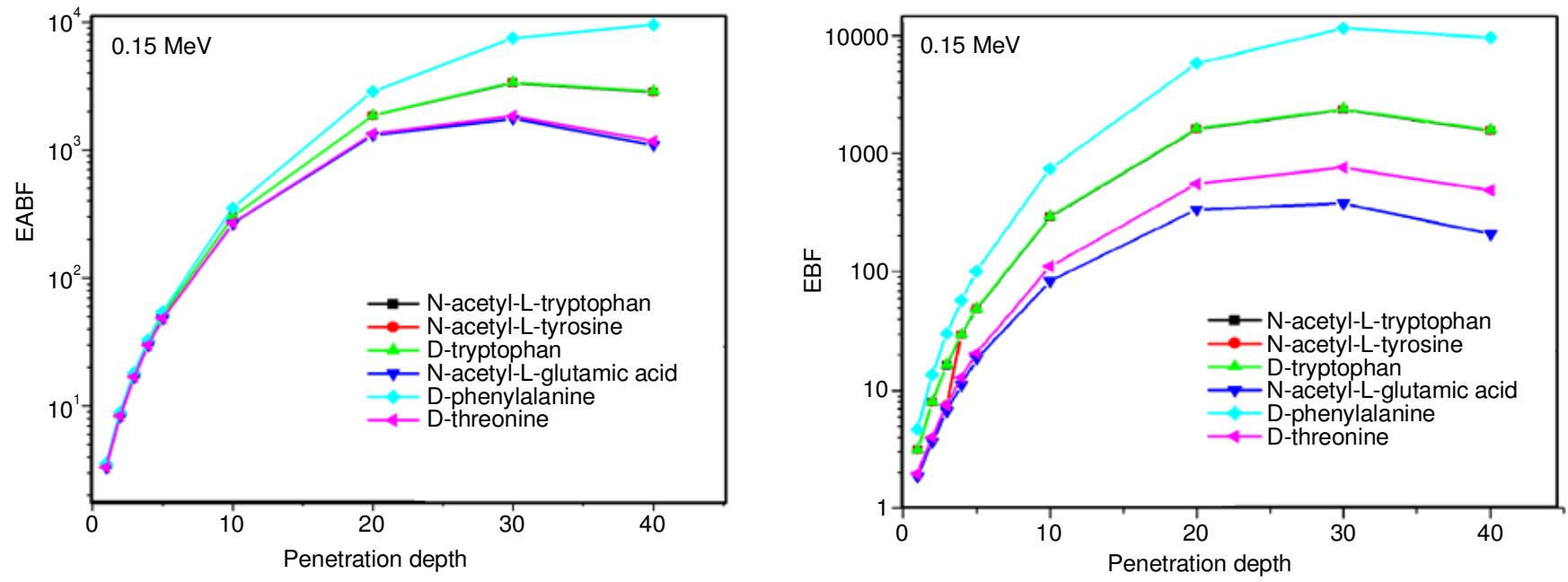

Fig. 5. Variation of EABF and EBF with penetration depth upto $40 \mathrm{mfp}$ at $0.1 \mathrm{MeV}$
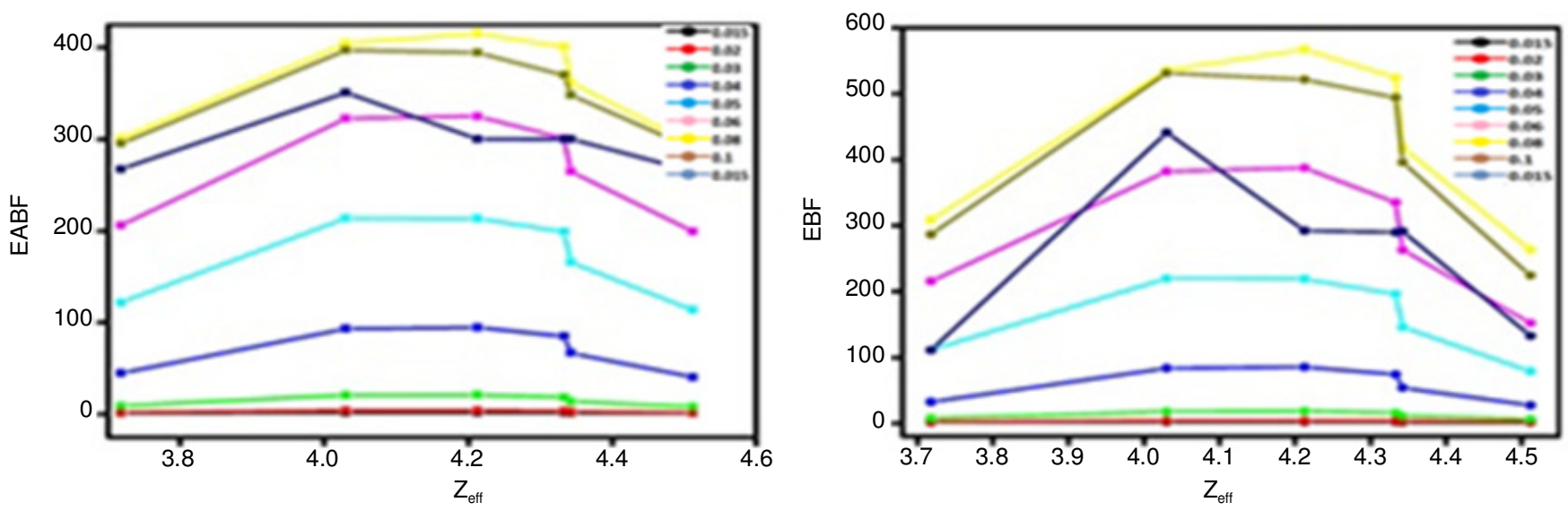

Fig. 6. Variations of EABF and EBF with $\mathrm{Z}_{\mathrm{eff}}$ at selected energy region
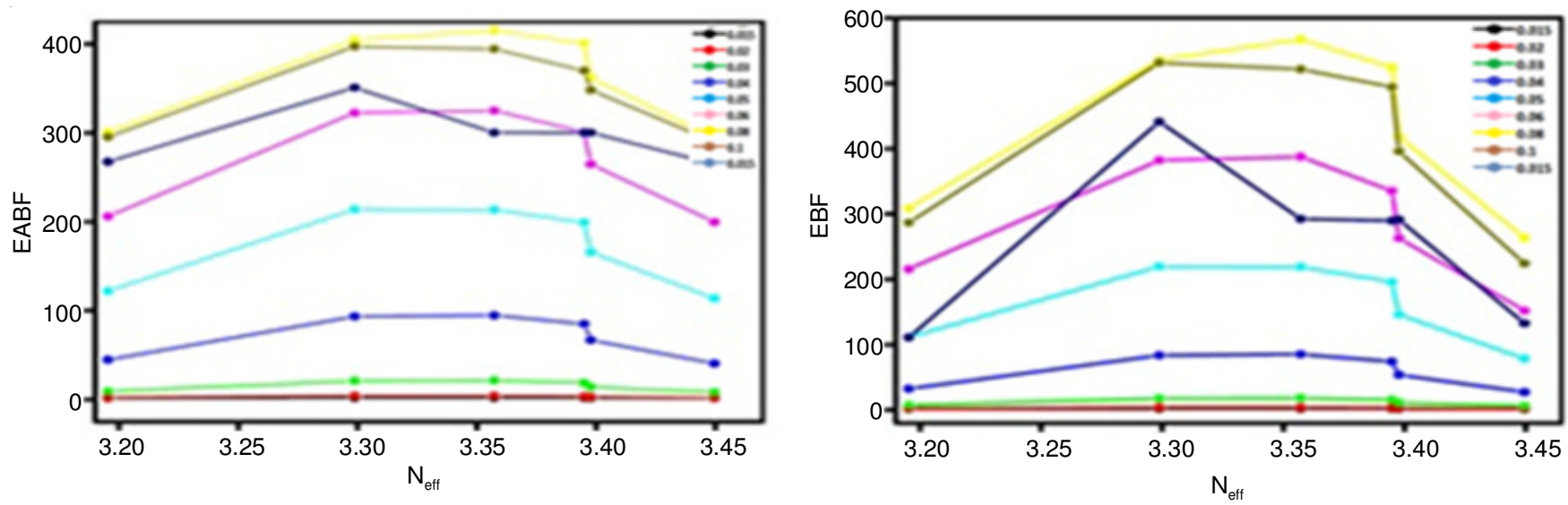

Fig. 7. Variations of EABF and EBF with $\mathrm{N}_{\text {eff }}$ at selected energy region

treatment it gives the accurate information about dose distribution without harm to normal tissue viz. high radiation dose to tumours.

\section{Conclusion}

In the present study mass attenuation coefficients, effective atomic number $\left(\mathrm{Z}_{\text {eff }}\right)$ and effective electron density $\left(\mathrm{N}_{\text {eff }}\right)$ at wide energy range $1 \mathrm{keV}$ to $100 \mathrm{GeV}$ and $\mathrm{EABF}$ and EBF were calculated by using G-P fitting method at 0.015 to $15 \mathrm{MeV}$ upto penetration depth 40 MFP using ANS/ANSI database of unnatural amino acids. The $\mathrm{Z}_{\text {eff }}$ and $\mathrm{N}_{\text {eff }}$ vary with photon energy, energy increases $\mathrm{Z}_{\mathrm{eff}}$ and $\mathrm{N}_{\text {eff }}$ decreases. The study gives idea of interaction process with EABF and EBF. EABF and EBF values were the highest and their Compton scattering is the main interaction process. EABF and EBF with function of $\mathrm{Z}_{\text {eff }}$ and $\mathrm{N}_{\text {eff }}$ shows that as the value of EABF and EBF increases, $\mathrm{Z}_{\text {eff }}$ and $\mathrm{N}_{\text {eff }}$ spontaneously decreases. This theoretical study investigate a new approach to biological materials on different penetration depth at different energy range and gives the information about their physical, chemical and biological properties. 


\section{ACKNOWLEDGEMENTS}

One of the authors (RML) is thankful to University Grant Commission, New Delhi, India to providing the Rajiv Gandhi National Fellowship (Award Letter No. F1-17.1/2013-14/RGNF2013-14-SC-MAH-45715) to pursue Ph.D. Degree .

\section{REFERENCES}

1. S. Manohara, S. Hanagodimath and L. Gerward, J. Appl. Clin. Med. Phys. 12, 296 (2011);

https://doi.org/10.1120/jacmp.v12i4.3557.

2. S. Gowda, S. Krishnaveni, T. Yashoda, T. Umesh and R. Gowda, PramanaJ. Phys., 63, 529 (2004); https://doi.org/10.1007/BF02704481.

3. E. Bursalioglu, B. Balkan, H. Kavanoz, M. Okutan, O. Eçelli and Z. Yaçin. BioMed. Res. Int., Article ID 359754 (2014); https://doi.org/10.1155/2014/359754

4. M. Kurudirek, B. Dogan, M. Ingec, N. Ekinci and Y. Ozdemir, Appl. Radiat. Isot., 69, 381 (2011);

https://doi.org/10.1016/j.apradiso.2010.11.007.

5. J. Dhillon, B. Singh and G. Sidhu, IOSR J. Appl. Physics, 1, 14 (2012); https://doi.org/10.9790/4861-0161421.

6. G. Sidhu, P. Singh and G. Mudahar, J. Radiol. Prot., 20, 53 (2000); https://doi.org/10.1088/0952-4746/20/1/306

7. H. Manjunatha and B. Rudraswamy, Radiat. Phys. Chem., 80, 14 (2011); https://doi.org/10.1016/j.radphyschem.2010.09.004.

8. B. Singh, V. Kumar, M. Devi and G. Sidhu, Int. J. Latest Res. Sci. Technol., 5, 65 (2013).

9. Y. Harima, Y. Sakamoto, S. Tanaka and M. Kawai, Nucl. Sci. Eng., 94, 24 (1986); https://doi.org/10.13182/NSE86-A17113.

10. Y. Sakamoto, S. Tanaka and Y. Harima, Nucl. Sci. Eng., 100, 33 (1988); https://doi.org/10.13182/NSE88-A29012.
11. A. Shimizu, J. Nucl. Sci. Technol., 39, 477 (2002); https://doi.org/10.1080/18811248.2002.9715225.

12. C. Suteau and M. Chiron, Radiat. Prot. Dosimetry, 116, 489 (2005); https://doi.org/10.1093/rpd/nci192.

13. D. Sardari, A. Abbaspour, S. Baradaran and F. Babapour, Appl. Radiat. Isot., 67, 1438 (2009); https://doi.org/10.1016/j.apradiso.2009.02.033.

14. S. Manohara and S. Hanagodimath, Nucl. Instrum. Methods Phys. Res. $B$, 258, 321 (2007); https://doi.org/10.1016/j.nimb.2007.02.101.

15. Y. Sakamoto, T. Suzuki, O. Sato and H. Hirayama, Prog. Nucl. Sci. Technol., 37, 484 (2000); https://doi.org/10.1080/00223131.2000.10874933.

16. M.J. Berger and J.H. Hubbell, 1987/1999 XCOM: Photon Cross Section Database,Web Version 1.2, National Institute of Standards and Technology, Gaithersburg, MD 20899, USA (1999).

17. ANSI/ANS-6.4.3., Gamma Ray Attenuation Coefficient and Buildup Factors for Engineering Materials, American Nuclear Society, La Grange Park, Illinois, USA (1991).

18. A. El-Khayatt, A. Ali, V. Singh and N. Badiger, Radiat. Eff. Defects Solids, 169, 1038 (2014); https://doi.org/10.1080/10420150.2014.988626.

19. C.V. More, R.M. Lokhande and P.P. Pawar, Radiat. Phys. Chem., 125, 14 (2016); https://doi.org/10.1016/j.radphyschem.2016.02.024

20. M.I. Sayyed and H. Elhouichet, Radiat. Phys. Chem., 130, 335 (2017); https://doi.org/10.1016/j.radphyschem.2016.09.019.

21. S. Gounhalli, IOSR J. Appl. Phys., 2, 40 (2012); https://doi.org/10.9790/4861-0244048.

22. E.A. Ryan, M.J. Farquharson and D.M. Flinton, Phys. Med. Biol., 50, 3337 (2005); https://doi.org/10.1088/0031-9155/50/14/010. 